\title{
sobre: La visitación. Ensayo sobre la narrativa de Antonio Di Benedetto, de Rafael Arce. Buenos Aires: La Cebra, 2020.
}

\author{
MARTÍN KOHAN Universidad de Buenos Aires, Argentina
}

ORCID 0000-0001-6650-6547

martindiegokohan@gmail.com

Hay novelistas para quienes narrar no supone más que narrar, y los hay para quienes narrar no es posible sin a la vez preguntarse el cómo. Podría decirse, de manera análoga, que hay críticos para quienes leer no supone más que leer, y los hay para quienes leer no es posible sin preguntarse el cómo. Y hasta hacen de ese cómo su objeto primordial, más allá del objeto puntual con el que esa lectura funciona. Cuando Rafael Arce lee a Antonio Di Benedetto en La visitación, tal como lo hizo antes a propósito de Juan José Saer, responde exactamente a esa inquietud de autoconciencia, por la que la lectura de los textos de Di Benedetto no tratará de discernir esos textos tan solo, sino también, y especialmente, en qué consiste esa misma lectura, qué es lo que concretamente hace, y a la vez, lo que no se hace, es decir, cómo no leer. No todas las literaturas soportan esta clase de abordaje, el que procura poner en juego toda una concepción de la literatura misma; y no toda crítica literaria (incluso siendo muy buena) asume ese desafío. Rafael Arce ciertamente lo hace, y no es por azar que elige los textos que elige. La pregunta por la literatura como tal, tan propensa de por sí a las vaguedades más irrisorias o a las más inciertas metafísicas, cobra en cambio, de este modo, un carácter visceral y específico, el espesor tangible de una práctica de lectura, la consistencia inexorable de una motivación y de una necesidad.

Hay dos afanes, dos ambiciones que Arce se plantea ya en el comienzo del libro (son eso: afanes, ambiciones, y no meramente objetivos; aunque «objetivos» sea el término que imponen habitualmente los formularios administrativos, incluso a los enfoques críticos que luego sostendrán nociones como contingencia y acontecimiento, así como a los que sostendrán la proliferación de lo abierto le impondrán la palabra «conclusiones», y a los que sostendrán la deriva del sentido le exigirán «palabras clave»). Lo que Arce se propone es defender en Di Benedetto la singularidad de lo que de repente se ha vuelto demasiado visible; y apenas unas páginas después, en un registro ya casi utópico, «atrapar el instante en que se inventan valores». Y eso porque, por un lado, la excentricidad de Di Benedetto ya parece haberse vuelto un tópico, y con eso, haberlo centrado. Y por el otro, en consecuencia, el problema que se plantea no es solamente el de la valoración literaria, sino más bien el de los criterios de producción y asignación de valor.

Para citar este artículo: Kohan, M. (2021). Sobre: La visitación. Ensayo sobre la narrativa de Antonio Di Benedetto, de Arce, R. El taco en la brea, (13) (diciembre-mayo). Santa Fe, Argentina: UNL. eoo43 DOI: 10.14409/tb.v1i13.10240 
El rescate crítico de Di Benedetto (esas operaciones de rescate de olvidados o marginados que cada tanto emprende la crítica) está ya plenamente logrado; de no leído o poco leído ya ha pasado a leído y hasta a bastante leído. Pero es por eso precisamente que Arce plantea la posibilidad, o más bien la necesidad, de preguntarse cómo leerlo, o de discutir cómo se lo lee. Por empezar, y con una fuerte decisión, sacarlo de la «hegemonía de la negatividad», la de un pesaroso existencialismo humanista, la que asigna a la imaginación y a la fantasía apenas un carácter de frustrante imposibilidad, la que solo permite ver un sesgo lúgubre en la angustia y la desgracia, sin percibir la faceta ridícula que Di Benedetto acierta a imprimirles. Arce apunta así a reconocer lo cómico de la literatura de Di Benedetto, la potencia (y no solo la carencia) de lo imaginario, la «afirmación de una intensidad impersonal» en la animalidad o en la destrucción del yo corporal, la espera (de Zama) como un ejercicio y no ya como inacción.

Leer a Di Benedetto, preguntarse cómo leer a Di Benedetto, es lo que lleva a Rafael Arce a retomar a Sergio Chejfec y su lectura desde la noción de verdad, pero ajustándola a la verdad del afecto (y no la del realismo); a volver a la lectura que de "Aballay» hizo Julio Premat, pero para producir a partir de ahí un desvío; a socavar los abordajes simbólicos o metafóricos de sus fábulas; incluso a leer a partir de una condición de autor, pero sin por eso atenerse a la obra como un objeto dado. La teoría funciona en La visitación bajo esa premisa sostenida de una lectura que piensa y se piensa: no se trata de aplicar teorías (Arce discute por caso la aplicación de Todorov al género fantástico; no porque su esquema no funcione, sino porque funciona demasiado bien), ni tampoco de emplearlas para «resolver» los textos (ahí donde la resolución no es sino la eximición de leerlos). Lo que hace que Arce desista de Sartre y prefiera a Blanchot, lo que hace que a la noción de libertad de Sartre prefiera la de soberanía de Bataille, lo que hace que Bataille pueda resultar preferible a Heidegger, no es una determinación que permite orientar las lecturas; es el recorrido que las propias lecturas piden y que las propias lecturas proponen. Lecturas que pueden suscitar una puesta en contexto (la espera de Zama en un mismo «compás de espera», un mismo «tiempo de suspensión y aplazamiento» que atraviesa América a fines del siglo XVIII), un lazo de intertexto (de «Aballay» a «El artista del trapecio» de Kafka y luego al «Bartleby...» de Melville: renuncia y procastinación) o concentrarse en los procedimientos textuales (la abstracción en El pentágono como «una consecuencia de este trabajo sustractivo de la imaginación»).

A diferencia de lo que pasa con las teorías empleadas como recetas de aplicación mecánica, o con las modas teóricas y su pret-a-porter de cada temporada lanzadas desde las casas matrices a las filiales universitarias del mundo, taras de lectura por las cuales se termina diciendo más o menos lo mismo de los autores más dispares y las literaturas más discordantes, Rafael Arce da cuenta de la diversidad que se aloja al interior de los textos de Di Benedetto, sobre la base, simple pero contundente, de no leerlo siempre igual. Es eso lo que le otorga a su lectura la plasticidad necesaria para ir de la oscuridad de lo indistinto en El pentágono a la claridad de los Cuentos claros sin caer en la tentación de aclarar esa oscuridad, primero, y pudiendo después apreciar el gesto de resistencia que supone pasar a la nitidez realista para no dejar que la extrañeza antes practicada se coagule y se codifique.

Podría decirse, en ese sentido, que así procede Arce en La visitación: da cuenta de esa extrañeza sin él mismo codificarla, es sensible a la singularidad de Di Benedetto y no precisa resolverla. Arce no lee todos los libros de Di Benedetto. Tampoco cierra La visitación recapitulando y concluyendo. Evita la totalidad, prescinde del cierre. Hay en eso un tono y hay en eso un gesto. Ese tono y ese gesto son, desde su enunciación, también una forma más que atinada para leer a Di Benedetto. 